Part of Journal of Research of the National Bureau of Standards, Volume 13. December 1934

\title{
COMPARISON OF THE GROUND-PLANE AND IMAGE METHODS FOR REPRESENTING GROUND EFFECT IN TESTS ON VEHICLE MODELS
}

\section{By Roy H. Heald}

\section{ABSTRACT}

In order to simulate full-scale conditions when vehicle models are tested in the wind tunnel it is necessary to represent the presence of the ground. Approximate representation of ground effect can be obtained by means of either the fixed ground-plane method or the image method. An experimental comparison of the two methods, in which concordant results were obtained, is described and the results are discussed from the viewpoint of present knowledge of air flow.

\section{CONTENTS}

II. Experimental comparison of the image and ground-plane methods 865

1. Experimental procedure . .

2. Results

(a) Velocity pressure measurements

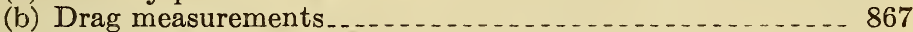

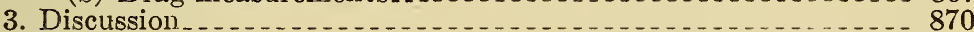

III. Conclusion $\ldots \ldots \ldots$

\section{INTRODUCTION}

Two methods for investigating the air resistance of vehicles have become established. The more direct one is by means of road tests, using full-scale equipment, but because of the expense involved and the difficulty of securing accurate comparative data, this method appears better suited for final performance tests. The wind-tunnel method, using models, while less direct has the advantage of convenience and comparatively low cost, both items of some importance if it is desired to conduct a systematic study of the air forces on a considerable number of body forms. While the use of the results of wind-tunnel tests for estimating full-scale forces is not entirely satisfactory because of the lack of precise knowledge of the effect of the scale of the model and the effect of turbulence in the wind tunnel, the results do constitute valuable guides in design.

The early use of wind-tunnel measurements on models as a basis for estimating the air forces acting on moving vehicles is associated with the experiments conducted by Goss and Solberg ${ }^{1}$ on models of

\footnotetext{
1 Proc. Western Ry. Club 10, 347 (1898).
} 
railroad trains. More recent investigations, particularly those dealing with the development of new body shapes for automobiles, also have been confined largely to wind-tunnel experiments. One of the problems arising in this connection is that of representing the effect of the presence of the ground on the air resistance of a moving vehicle.

While the possibility of the effect of aerodynamic interference between a moving vehicle and the ground has been recognized, no sound and practical method for its evaluation in the wind tunnel has been given. The problem is one of relative motion. When a vehicle is driven in still air, the relative motion between the ground and the surrounding air is zero; the motion of the full-scale vehicle is therefore with respect to both the ground and the air. In the wind tunnel the air moves with respect to both the model and the ground plane. Thus the wind-tunnel arrangement represents actually only the condition when the vehicle is stationary and a horizontal wind blows against it. A closer approximation of the actual conditions is obtainable by means of a belt moving close beneath the model in the wind tunnel, its linear velocity being adjusted so that the relative motions of the air stream, the model, and the belt simulate full-scale conditions. The mechanical difficulties inherent in this method of representing the ground effect are numerous and consequently some more easily used method has been sought.

The method of images, described by Rumpler, ${ }^{2}$ is designed to replace the direct representation of ground effect in the wind tunnel. As implied by the title it involves measurement of the air force on duplicate models, one inverted, fastened wheel to wheel. See figure 1 (B) and (C). The drag of the pair is determined and one-half the net drag is taken to represent the drag of one model. This method is dependent on the assumption that the laws of air flow apply in precisely the same way to the duplicate model set-up as to the actual vehicle moving along the ground, an assumption whose validity is not established. The experimental background is made up of the results of some investigations in which, to a large extent, the model and fullscale measurements are uncorrelated. The conclusion to be drawn from a study of available data is that the full-scale forces are of the order of magnitude to be expected from model tests but the comparisons are uncertain, because of the probable effects of Reynolds number and wind-tunnel turbulence.

In an extensive investigation, the construction of accurate models in duplicate is tedious and costly. Both time and expense can be saved by the use of a single model. Hence the ground-plane method, which consists in testing one model close to a large stationary platform in the wind tunnel, has come into use. The results obtained by either of the methods must be regarded as comparative only, since neither method has been shown to be an exact representation of actual conditions.

A few experimental comparisons which show good agreement between the ground-plane and image methods have been made. Others indicate decided lack of agreement. Consideration of the results of recent investigations, among them the work of Hansen, ${ }^{3}$

2 Zeit. f. Flug. u. Motoriuft. 15, 22 (1924).

3 Nat. Adv. Comm. Aeron. (October 1930), Tech. Memo. 585. 


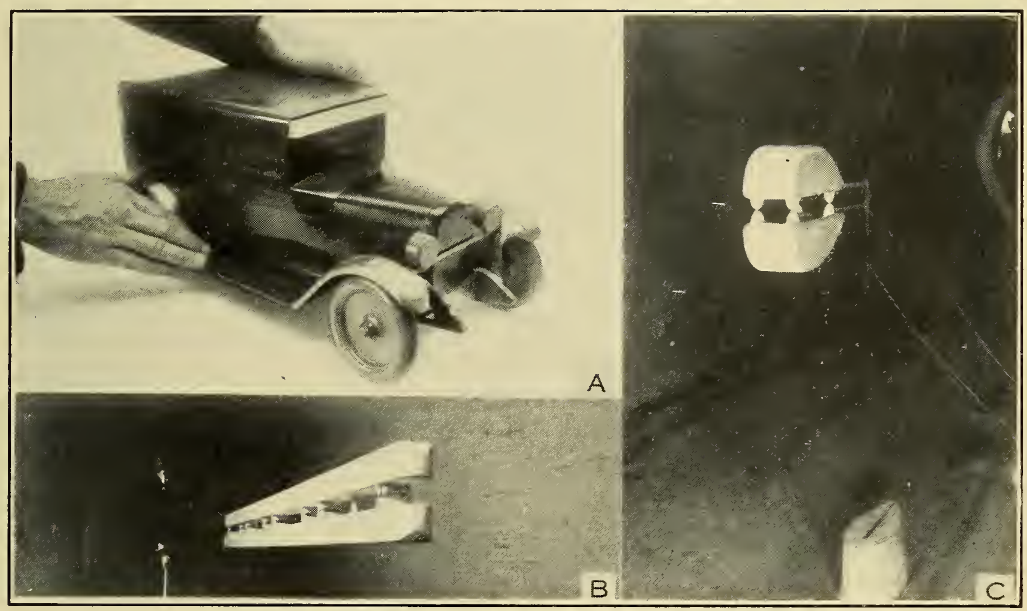

FIGURE 1.-Vieus of the models used for comparing the image and ground-plane methods. 
concerning the velocity distribution in the boundary layer ${ }^{4}$ of a flat plate, led to the belief that the discordance might be ascribed to an effect of the shape of the leading edge of the platform in the case of the ground-plane method.

\section{EXPERIMENTAL COMPARISON OF THE IMAGE AND GROUND-PLANE METHODS}

It appeared desirable to investigate the effect of the shape of the leading edge of the ground plane on the results of drag measurements and to compare the image and ground-plane methods. For this purpose two types of models were constructed, one representing in general proportions a railroad train, the other a streamline automobile. $^{5}$ Views of the models arranged for tests using the image method are shown in figure 1 (B) and (C). In some earlier experiments a model of a conventional automobile, shown in figure 1 (A), was used. In addition to measurements of drag, the speed distribution near the ground plane was measured for two types of leading edge.

\section{EXPERIMENTAL PROCEDURE}

The arrangement of the apparatus for measuring the air resistance of the train and streamline automobile model is shown in figure 2.

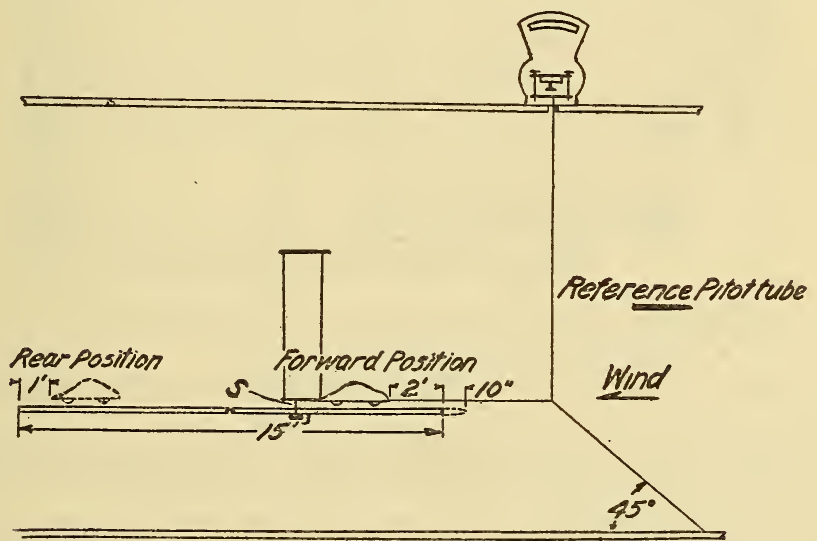

Figure 2.-Arrangement of apparatus used for the ground-plane method.

The platform was $81 \frac{1}{2}$ feet wide extending completely across the wind tunnel. Its upper surface was $2 \frac{1}{2}$ feet above the floor of the wind tunnel.

The automobile models were supported by vertical steel wires having a diameter of 0.0085 inch; the train models by wires of diameter 0.02 inch. A single fine wire extended horizontally, from the nose of the

4 The distribution of velocity in the boundary layer (before separation) of a body moving with uniform velocity in still air can be visualized as follows: At the surface of the body the air is at rest with respect to the body. A short distance out from the surface the velocity is finite although small. As the distance from the surface increases the velocity with respect to the body increases until it becomes equal to the velocity of the body with respect to the ground, i. e., the air is undisturbed and is stationary with respect to the ground. The boundary layer has no definite limit. Its thickness may bedefined as the distance from the surface required for the velocity to reach 99 percent of free stream velocity. On the basis of this definition the thickness, $\delta$, in feet, of the boundary layer at a distance, $x$ feet, from the sharpened leading edge of a flat plate is: $\delta=4.8 \sqrt{\frac{x \nu}{V}}$, where $\nu=0.00016 \mathrm{ft}^{2} / \mathrm{sec}$ at $15^{\circ} \mathrm{C}, 760 \mathrm{~mm} \mathrm{Hg}$ and $V$ is the velocity in feet per second.

$\checkmark$ As shown in figure 1 (B) and (C), these models resembled actual vehicles only in general shape. They were constructed for the particular purpose of comparing the 2 methods of representing ground effect for different body types. 
model to a point some 10 feet upstream, where it formea a junction with a 45-degree wire and a vertical wire running to the yoke on the balance. This arrangement gives equal tensions in the vertical and the 45-degree wires when a drag force is applied to the model. The model was maintained in a fixed position by means of an adjustable yoke mounted on the platform of a balance above the tunnel. The yoke being capable of fine adjustment, it was possible by focusing a telescope on a reference point on the model, to maintain the original position, very closely, during the taking of observations.

The two types of leading edge shown in figure 3 , were used in the experiments by the ground-plane method. Some measurements were made on the train and streamline automobile models at several different distances above the ground plane. In the case of the automobile model, drag measurements were made also for positions near the leading and trailing edges of the platform using the faired leading

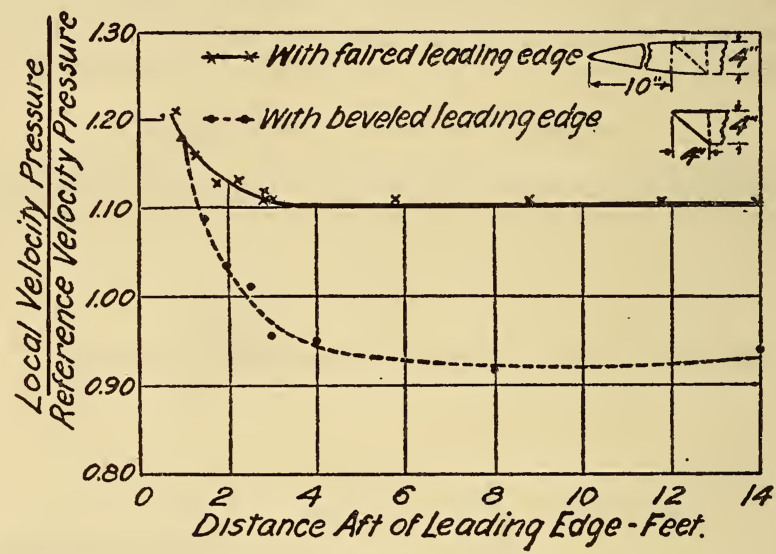

FIGURE 3.-Resulis of traverse along a median horizontal line, 3 inches above the ground plane.

The excess of the local velocity pressure over the reference velocity pressure results from the blocking effect of the platform and support.

edge. Velocity surveys were made above the platform in the vertical median plane, using both the beveled and faired leading edges, the pressures being measured by means of a Pitot-static tube and referred to the pressure readings of a reference Pitot-static tube mounted on a projecting strut above and some 2 feet ahead of the platform.

In the experiments by the image method, a housed counterweight was suspended by a small vertical wire several feet below the models; otherwise the suspension was similar to that used with the ground plane. The drag of this wire and the drag of 4 small pins (diameter, 0.10 inch) which served to hold the models together was computed and deducted from the total observed drag, leaving the drag of 2 models, 2 stings, and 8 wires. A small correction also was necessary for the drag of the counterweight spindle $S$, figure 2 , in the case of ground-plane method. Pressure drop corrections were not applied. ${ }^{6}$

6 The pressure drop or buoyancy correction is sometimes applied to the results of drag measurements of models. The correction is based on the drop in static pressure in the part of the tunnel where the model measurements are made. If the model drag is measured in pounds, the pressure drop correction, in pounds, assuming a uniform pressure gradient, is given by the formula $\left(p_{1}-p_{2}\right) \frac{C}{l}$, where $p_{1}$ and $p_{2}$ are the pressure at the front and rear of the model position in feet of water. $C$ and $l$ are respectively, the volume, in cubic feet, and the length, in feet, of the model. The correction is subtractive, but in the case of short models is usually so small that it can be neglected. 


\section{RESULTS}

(a) VELOCITY PRESSURE MEASUREMENTS

The results of the velocity pressure survey are plotted in figures 3 and 4 . Figure 3 refers to a median horizontal line 3 inches above the platform extending from leading edge to trailing edge; figure 4 to a vertical line 2 feet downstream from the leading edge. It will be seen that the shape of the leading edge exerts a substantial influence on the velocity distribution in the neighborhood of the platform. Although the curves are nearly coincident for a position 1 foot downstream from each leading edge, the curve for the beveled edge shows a more rapid decrease in velocity as the trailing edge is approached. The faired leading edge gave rise to substantially uniform velocity in the 3 -inch horizontal pane, beginning about 3 feet back from the leading edge.

The difference is shown more clearly, figure 4, in the traverse along a vertical line 2 feet aft of the leading edge. The beveled leading edge

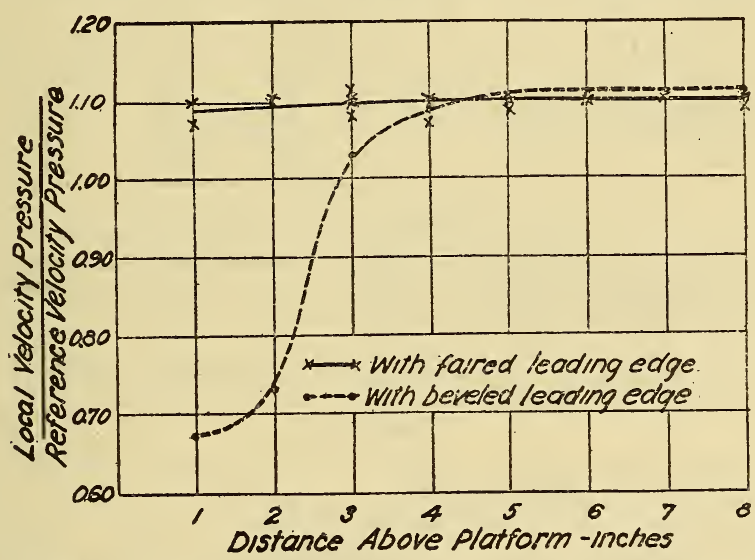

FIgURE 4.-Results of traverse along a vertical line 2 jeet aft of the leading edge of the ground plane.

The excess of the local velocity pressure over the reference velocity pressure at some distance from the ground plane is due to the blocking effect of the platform and support.

caused a rapid decrease in velocity pressure, beginning about 4 inches above the surface of the platform. One inch above the platform the local velocity pressure was found to be about two-thirds of the velocity pressure in the free stream. With the faired leading edge on the other hand, there was little decrease at the 1-inch station. The theoretical thickness of the boundary layer for a thin plate is about 1.3 inch for the average speed $(60 \mathrm{ft} / \mathrm{sec})$ at which the traverses were made.

\section{(b) DRAG MEASUREMENTS}

The results of the drag measurements are given in tables 1 to 3 . Tables 1 and 2 give the results of the comparison using the streamline automobile models, table 1 being a sample summary sheet. In these 2 tables, one-half the drag of the 2 models and the support system, as determined by the image method, is compared with the drag of 1 model and its support system, as determined by the ground-plane

$94127-34-8$ 
method. The observed values of the total drag for several speeds were divided by the square of the corresponding speeds and the mean values of this ratio together with the mean deviations are given in table 2. The use of a ratio based on total drag eliminates the errors arising from the determination of support correction.

\section{TABLE 1.-Summary sheet of tests on streamline automobile models}

Figure $1(\mathrm{C})$

\begin{tabular}{|c|c|c|c|c|c|}
\hline Method & $\begin{array}{c}\text { Air } \\
\text { speed } \\
\text { mph } \\
V\end{array}$ & $\begin{array}{l}\text { Total } \\
\text { drag }\end{array}$ & $\begin{array}{l}\text { Correc- } \\
\text { tions }\end{array}$ & $\begin{array}{c}\text { Drag of } 1 \\
\text { model } 4 \\
\text { wires and } \\
\text { sting } \\
D\end{array}$ & $\frac{D}{V^{2}}$ \\
\hline $\begin{array}{l}\text { Ground-plane method.-Platform with faired leading } \\
\text { odge. Forward position of model. Wheels } 1 / 16 \\
\text { inch above platform. }\end{array}$ & $\begin{array}{l}54.3 \\
55.4 \\
56.6 \\
57.8 \\
58.9\end{array}$ & $\begin{array}{r}\text { Pounds } \\
0.312 \\
.326 \\
.332 \\
.346 \\
.356\end{array}$ & $\begin{array}{r}\text { b. } 009 \\
.009 \\
.009 \\
.010 \\
.010\end{array}$ & $\begin{array}{r}0.303 \\
.317 \\
.323 \\
.336 \\
.346\end{array}$ & $\begin{array}{r}0.000103 \\
103 \\
101 \\
101 \\
100\end{array}$ \\
\hline Mean.- & - & - & - & - & d 0.000102 \\
\hline $\begin{array}{l}\text { Image method.-Models suspended } 31 / 2 \text { feet above } \\
\text { platform, } 1 / 8 \text {-inch space between wheels. }\end{array}$ & $\begin{array}{l}54.8 \\
56.1 \\
57.1 \\
58.4 \\
59.5\end{array}$ & $\begin{array}{r}0.654 \\
.674 \\
.702 \\
.731 \\
.752\end{array}$ & $\begin{array}{r}\circ 0.020 \\
.021 \\
.022 \\
.023 \\
.023\end{array}$ & $\begin{array}{r}0.317 \\
.327 \\
.340 \\
.354 \\
.365\end{array}$ & $\begin{array}{r}0.000106 \\
104 \\
104 \\
104 \\
103\end{array}$ \\
\hline Mean. & & . & & -..... & $\cdot 0.000104$ \\
\hline
\end{tabular}

a Speed in the free stream 2 feot ahead of the model.

$b$ Computed for counterweight spindle.

d Mean deviation 1.2 percent.

c Computed for holding pins and counterweight wire.

- Mean deviation 0.6 percent.

TABLE 2.- $\frac{D}{V^{2}}$ for streamline automobile models ${ }^{a}$

Figure $1(\mathrm{C})$

\begin{tabular}{|c|c|c|c|c|c|}
\hline \multirow{3}{*}{$\begin{array}{c}\text { Wheel } \\
\text { clearance }\end{array}$} & \multicolumn{3}{|c|}{ Ground-plane method } & \multirow{3}{*}{ Image method } & \multirow{3}{*}{$\begin{array}{l}1 \text { model at center } \\
\text { of tunnel, i. e., } \\
\text { ground not rep- } \\
\text { resented }\end{array}$} \\
\hline & \multicolumn{2}{|c|}{ Faired leading edge } & \multirow{2}{*}{$\begin{array}{c}\begin{array}{c}\text { Beveled leading } \\
\text { edge }\end{array} \\
\text { Forward position }\end{array}$} & & \\
\hline & Forward position & Rear position & & & \\
\hline $\begin{array}{l}\text { Inch } \\
1 / 16 \\
5 / 16 \\
9 / 16\end{array}$ & $\begin{array}{l}0.000102 \pm 1.2 \% \\
0.000103 \pm 0.7 \% \\
0.000106 \pm 0.6 \%\end{array}$ & $\begin{array}{l}0.000104 \pm 0.2 \% \\
0.000101 \pm 1.0 \% \\
0.000096 \pm 0.4 \%\end{array}$ & $\begin{array}{l}0.000095 \pm 0.4 \% \\
0.000090 \pm 0.4 \% \\
0.000091 \pm 0.8 \%\end{array}$ & $\begin{array}{l}0.000104 \pm 0.6 \% \\
0.000104 \pm 1.0 \% \\
0.000104 \pm 0.6 \%\end{array}$ & $0.000115 \pm 1.0 \%$ \\
\hline
\end{tabular}

a $D$ refers to drag of 1 modol, the sting and 4 wires. Mean value $\frac{\text { Drag of support system }}{V^{2}}=0.000039$. Projected frontal area of 1 model $=0.0975 \mathrm{sq} f$.

TABLE 3.- $\frac{D}{V^{2}}$ for conventional automobile model a

Figure 1 (A)

\begin{tabular}{|c|c|c|}
\hline $\begin{array}{c}\text { Wheel } \\
\text { clearance }\end{array}$ & $\begin{array}{c}\text { Ground-plane } \\
\text { method }\end{array}$ & Image method \\
\hline $1 / 16$ inch--- & $0.000728 \pm 1.8 \%$ & $0.000744 \pm 0.7 \%$ \\
\hline
\end{tabular}

a $D$ refers to net drag of one model. Projected frontal area of one model $=0.393 \mathrm{sq} \mathrm{ft}$. 
The results for the ground plane with faired leading edge show good agreement with those obtained by the image method for both forward and rear positions. With the model in the forward position above the ground plane and with the beveled leading edge in place, the values of $\frac{D}{V^{2}}$ obtained by the ground-plane and the image methods differed by some 12 percent. When the drag of the support wires was subtracted, the divergence was of the order of 22 percent of the net drag of the model. This discordance is not surprising in view of the results of the velocity survey above the ground plane, since the shape of the leading edge was found to exercise a marked effect on the thickness of, and the velocity distribution in, the boundary layer of the ground plane. The results of this part of the investigation indicate that the shape of the leading edge of the ground plane is an important factor in determining the drag of a faired model tested near the plane.

The effect of raising the model slightly above the platform, i. e., of wheel clearance, was found to be small, presumably because of the fact that the body proper, even in the nearest position, was separated from the platform by an amount slightly greater than the wheel radius, and hence was largely out of the region of low-speed air.

The results of the earlier comparative tests on a model of a conventional automobile (figure $1(A)$ ) are given in table 3 . In this case the model was suspended by four wires arranged in V's at the front and rear, the total drag being computed from the observed displacement of the model due to the wind, the swinging radius, and the weight. Although this procedure involved some uncertainty because of the upward displacement of the model with respect to the platform, relatively good agreement was found between the results obtained by the two methods.

The results for the train model with the trucks and wheels removed, table 4, show differences of about 5 percent, the ground-plane method giving the higher value. When the wheels and trucks were in place, the drag of the model was considerably greater, and the two methods gave substantially the same result. The difference between the results obtained by the two methods when the trucks and wheels were removed is presumably associated with the presence, in close proximity, of large, smooth surfaces in the ground-plane method, the drag being largely skin friction. Since neither method corresponds to the actual case in which the train moves relative to the ground and the air is at rest relative to the ground, it is not known which value is the more nearly applicable to a moving train.

TABLE 4.- $\frac{D}{V^{2}}$ for irain models ${ }^{a}$

Figure 1 (B)

\begin{tabular}{|c|c|c|c|}
\hline $\begin{array}{l}\text { Body clear- } \\
\text { ance }\end{array}$ & $\begin{array}{l}\text { Ground-plane } \\
\text { method, faired } \\
\text { leading edge }\end{array}$ & Image method & Remarks \\
\hline Inch & $0.000198 \pm 0.2 \%$ & $0.000189 \pm 0.2 \%$ & \multirow{3}{*}{$\begin{array}{l}\text { Without trucks and wheels } \\
(A=0.091 \text { sq } \mathrm{ft}) \text {. } \\
\text { without trucks and wheels } \\
(A=0.091 \text { sq } \mathrm{ft}) \text {. } \\
\text { with trucks and wheels } \\
(A=0.111 \text { sq } \mathrm{ft}) \text {. }\end{array}$} \\
\hline $11 / 4 \ldots$ & $0.000218 \pm 0.2 \%$ & $0.000209 \pm 0.1 \%$ & \\
\hline $11 / 4^{b} \ldots$ & $0.000367 \pm 0.2 \%$ & $0.000374 \pm 0.1 \%$ & \\
\hline
\end{tabular}

a refers to net drag of 1 model.

b Corresponds to wheel clearance of $3 / 16$ inch. 


\section{DISCUSSION}

The foregoing results indicate a possible source of discrepancy between the image and ground-plane methods. The speed of the air which acts on an object close to the ground plane is not the same as the speed of the air acting on the object several feet above it because of the presence of the boundary layer. In the experiments the beveled leading edge gave rise to a rapid decrease in velocity pressure beginning about 4 inches above the surface of the platform, corresponding to a comparatively thick boundary layer. For this reason agreement between the results of the two methods would not be expected. On the other hand concordant results were obtained when the faired leading edge was used, the velocity pressure in this case remaining practically uniform to within about 1 inch of the ground plane.

The results of the velocity traverse indicate the relative thicknesses of the boundary layers in the two instances. A model tested on the platform 2 feet aft of the beveled leading edge would obviously be subjected to a lower average velocity than when tested 2 feet aft of the faired leading edge, the reference speed being the same in the two cases. The result would be to cause lower drag measurements in the case of the beveled leading edge. The results of the drag tests on the streamline automobile model, table 2 , indicate the presence of an effect of this nature. Hence, in using the ground-plane method for determining the drag of streamline models it appears desirable to use a platform with a faired leading edge and to conduct the experiments sufficiently far downstream from the leading edge to obviate its effect on the drag of the model. The present measurements indicate that a distance of at least two model lengths is desirable.

\section{CONCLUSION}

In testing vehicle models in the wind tunnel some method must be used to represent the effect of the ground on the full-scale vehicle. A comparison of experimental results by the ground-plane and image methods indicates that good agreement may be expected if the leading edge of the ground plane is faired and the tests are conducted at least two model lengths behind the leading edge. The ground plane should extend completely across the air stream in order to maintain a uniform velocity distribution across the test section.

Washington, August 24, 1934. 